\title{
Über eine empfindliche Form der Quecksilberjodidreaktion.
}

\author{
Von \\ P. J ANNASCH.
}

Mit 1 Figur im Text.

Im Interesse des forensischen Nachweises geringer Quecksilbermengen in Leichenteilen unternahm ich mit Herrn H. LeHNenT zusammen eine Rejhe von Versuchen für die Feststellung der Ëmpfindlichkeitsgrenzen der bekanntesten Quecksilberreaktionen. Abgesehen von einer möglichen Gewinnung, wenigstens mit der Lupe sicher erkennbarer Quecksilberkügelchen, erwies sich uns der Quecksilberjodidbeschlag als am eigenartigsten und zuverlässigsten. Zur Verwendung als Corpus delicti stellt man diese Reaktion am vorteilhaftesten wie folgt an: Die aus den vorliegenden Objekten in der üblichen Art erzielte, nicht zu saure Quecksilberlösung wird genügend lange mit völlig blanken, dünnen Kupferschnitzeln in $\mathrm{Be}-$ rührung gelassen, das hierzu verwandte Erlenmeyerkölbchen ab und zu in lauwarmes Wasser stellend. Alsdann giefst man die Flüssigkeit ab, spült erschöpfend mit kaltem Wasser nach, schüttet den Inhalt auf Fliefspapier und entfernt mit solchem, nur zart tupfend, alles anhaftende Wasser, ohne das Metall selbst mit den Fingern zu berühren, worauf man dasselbe in ein $14-16 \mathrm{~cm}$ langes und 18 bis $22 \mathrm{~mm}$ weites Probeglas giebt und einige Sekunden die Luft darüber absaugt, um so die letzten Spuren etwa noch vorhandener Kondensationsfeuchtigkeit zu beseitigen. Dieses Rohr wird jetzt, wie nachstehende Figur zeigt, über dem gewöhnlichen Gasbrenner ausgezogen und kapillar verjüngt.

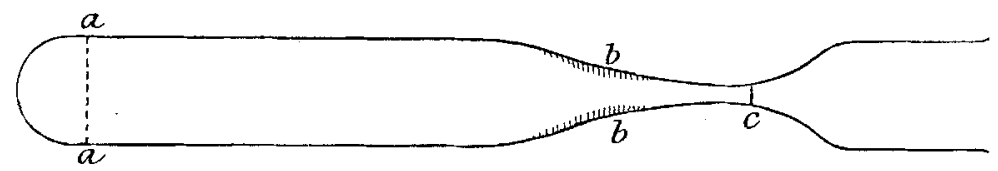

Man erhitzt alsdann rorsichtig über einer zollhohen Flamme, bis die Hauptmenge des sich bildenden Sublimats bei $b$ auftritt. Nach 
dem Erkalten des Rohres ritzt man das Glas bei a mit einer neuen, dreikantigen Glasfeile geschickt an, sprengt den ganzen Boden ab (am sichersten mit Sprengkohle) und schiebt nun diesen geöffneten Teil, lose von einem Korkring gehalten, in ein Stehcylinderchen, welches ein erbsengrol'ses Stück Jod enthält. Sobald sich nach Einwirkung der Joddämpfe ein deutlicher Beschlag von scharlachrotem (in dünnen Schichten gelbem) Quecksilberjodid gebildet hat, schmilzt man die Röhre bei $a$ und bei $c$ zur event. Verwendung als Beweisobjekt ab.

Die Empfindlichkeit dieser Reaktion, angestellt durch je $1 \mathrm{~cm}$ von Sublimatlösungen mit $1,0.1$ und $0.01 \mathrm{~g}$ pro $100 \mathrm{ccm}$ Wasser, war die folgende:

1. $0.01 \mathrm{~g}$ Quecksilberchlorid gaben eimen deutlichen Beschlag von metallischem Quecksilber und später desgleichen von Quecksilberjodid.

2. $0.001 \mathrm{~g}$ Quecksilberchlorid gaben einen sehwer erkennbaren Beschlag von metallischem Quecksilber, aber mit Jod deutlichen Beschlag von Quecksilberjodid.

3. $0.0005 \mathrm{~g}$ Quecksilberchlorid lieferten keinen ersichtlichen Hauch von metallischem Quecksilber mehr, dagegen mit Jod noch schwachen Jodidanflug.

4. $0.0001 \mathrm{~g}$ Quecksilberchlorid gaben keine sicher erkennbare Reaktion mehr, anch nicht bei Anwendung weit engerer Röhren als der oben erwähnten.

Durch ein weiteres Studium der chemischen Reaktionsbedingungen gelang es uns, einen noch höheren Empfindlichkeitsgrad für die Jodidbildung zu erzielen. $\mathrm{Zu}$ diesem Zweck verquickten wir ein Stückchen Kupferblech von $5-7 \mathrm{~mm}$ Kantenlänge mit $0.0001 \mathrm{~g}$ Quecksilberchlorid (1 ccm wässerige und schwachsaure Lösung in einem höchstens 8-10 ccm fassenden Bechergläschen). Das Kupfer ${ }^{1}$ wurde nach dem Abgiefsen der Quecksilberlösung u. s. f. mit Filtrierpapier vorsichtig getrocknet, hierauf auf ein Objektoder Uhrglas gebracht und getrennt davon, aber unmittelbar nahe ein halblinsengrolses Scheibchen $\boldsymbol{J}_{\text {od }}$ gelegt. Das ganze wurde nun mit einem Uhr- oder Krystallisierschälchen bedeckt kurze Zeit (5-10 Minuten) sich selbst überlassen. Hierbei bildete sich rings um das Metall herum (entweder aufsen oder darunter), genau in der Form des Bleches, ein ganz deutlicher Beschlag von Quecksilberjodid. Unter dem Mikroskop betrachtet, erscheint derselbe in

${ }^{1}$ Bei $1 / 10 \mathrm{mg}$ Sublimat ist die Verquickung des metallischen Kupfers noch vollkommen ersichtlich, aber nicht mehr bei 1/100 $\mathrm{mg}$ desselben. 
Form quadratischer Tafeln und viereckiger Oktaëder. Die kleinsten Krystalle sehen dunkel aus, die grölseren (bei stärkerer Anhäufung) im durchscheinenden Lichte dunkelrot, isoliert $=$ gelb, und aufserdem beobachtet man einzelne längliche Krystallisationen. ${ }^{1}$

In dieser Form erwies sich die Quecksilberjodidreaktion als überaus empfindlich, so dafs $0.00001 \mathrm{~g}$ Quecksilberchlorid = sieben millionstel Gramm metallisches Quecksilber, noch einen deutlichen Beschlag gaben.

1 H. BeHRens, Anleitung zur mikrochem. Analyse, S. 79 (L. Voss, Hamburg 1895).

Heidelberg, Universitätslaboratorium, Mär๘ 1896.

Bei der Redaktion eingegangen am 13. März 1896. 